\title{
The Method of Determining Importance of Criteria in a Multicriteria Decision Problem
}

\author{
Perminov Gennady Ivanovich, Leonova Nina Vjacheslavovna \\ National Research University Higher School of Economics, Moscow, Russian Federation
}

\begin{abstract}
Multi-criteria group decision-making tasks require the weights of the criteria. Assigning weights importance criteria by Individual Decision-makers (IDM) means, in essence, a priori assignment options for the winner. There are a number of problematic situations: (1) evaluation of alternatives represents a degree of satisfying the basic requirements of applicants. The assessment matrix is a small variation and a very large number of indicators (criteria); (2) application of cognitive maps for modeling of problem situations. If the alternatives are only considered as pure strategies (options affect the concepts), the matrix of evaluations is small size. If the task as alternatives to the use of mixed strategies (for example, $25 \%$ of the impacts on the concept $1,50 \%$ to $10 \%, 2$ concept for concept 3, etc.), then the matrix estimation is also becoming more dimension. It is clear that in such cases, the appointment of weighting criteria LPR becomes a problem. The goal is to develop a new method for obtaining the weight of each criterion according to alternatives from expert group upon receipt of examination results. First, this approach allows you to more accurately determine the rate the importance of each criterion, even with their large numbers. Second, it is now believed that the importance of the criterion is constant and independent of the expert, as well as from the problem situation, for which the conditions are evaluated. In terms of the authors propose a method to find the distances from the trajectories of alternatives for each criterion to build a perfect trajectory defined by the last method of finding commonality. The algorithm of the proposed method is as follows: (1) When a large number of indicators are the main factors that replace a baseline; (2) Are the regression coefficients for each criterion for generality; (3) Each evaluation of the alternatives, multiplied by every criterion found in (2) regression coefficients. Thus, the trajectory of each alternative is subject to Community criteria laid down in the original estimates; (4) On the path alternatives for each build criterion is the highest (or lowest depending on problem solving on Max or Min) score is a "record"; (5) According to various metrics is the matrix of distances of deviations from the ideal trajectory of alternatives (a record) of the path; and (6) The largest distance for each alternative, they are ranked and, thus, is the best. Implementation of the suggested method showed full convergence with the known method of weighting criteria for entropy in the matrix of evaluations of alternatives.
\end{abstract}

Keywords: decision-making, model TOPSIS, remoteness from the ideal trajectory of alternatives

\section{Introduction}

Multicriteria group problems of decision-making represent exclusively difficult class of problems of

Perminov Gennady Ivanovich, Associate Professor, Candidate of technical sciences, Department of business analytics, National Research University Higher School of Economics.

Leonova Nina Vjacheslavovna, Graduate Student, Master, Department of business analytics, National Research University Higher School of Economics.

Correspondence concerning this article should be addressed to Perminov Gennady Ivanovich, 141220, Pushkinsky district, Moscow region. Cheluskinsky, Water stalled st., 9A. E-mail: gperminov@hse.ru. 
intellectual activity of the person.

Are usually considered quantitative or rank rating scales? As a result of the decision of problem DSS at application of additive convolution, the calculated values for values for each alternative (Petrovsky, 2009) should turn out.

$$
U_{t}=\sum_{i=1}^{I} \sum_{j=1}^{J} \bar{V}_{t i j} \bar{W}_{i} \bar{D}_{j}
$$

where

$W_{i}$ : weight of criteria;

$D_{j}$ : factors of competence of experts of group examination;

$V_{t i j}$ : estimations of alternatives on $t$ to a variant, $i$ criterion, $j$ th expert;

$U_{t}$ : functions of value for each alternative $t$.

But in a number of problems of decision-making, an estimation of alternatives represents degree of satisfaction of the basic requirements to indicators of objects-applicants. The matrix of estimations thus differ small variability and a considerable quantity of indicators (criteria). The appointment of scales of importance to criteria, the Person Making Decisions (PMD) means, as a matter of fact, aprioristic appointment of a variant of the winner.

Another opportunity to get great ratings matrix dimension (as in the first case, more than 100) is the application of cognitive maps for simulating problem situations. If the alternatives are just pure strategies (options affect the concepts), matrix of evaluations is small size. If the task is permitted as an alternative to the use of mixed strategies (for example, 25\% of impacts on the concept 1, 50\% to $10 \%$, 2 concept for concept 3 , etc.), then the matrix evaluations are also more dimension.

Often there are other tasking decision-makings, resulting in large dimensions matrix evaluation of alternatives for criteria. It is clear that in such cases, the appointment of weighting criteria PDS becomes a problem.

Therefore, we can consider the possibility of determining the weights of the criteria in other ways.

Depending on methods and principles of reception of factors of competence of experts of group examination scales of criteria, estimations of alternatives on $t$ to a variant, $i$ criterion, $j$ th expert, and ways of averaging the set of approaches are offered:

- Transformation of ranks by values of monotonously decreasing functions of integer argument (Макаров, 1971; Tintarev \& Trofimov, 1975; Gmoshinsky \& Flnorent, 1975);

- Approximation of ranking by linear system of inequalities-(Charchmen \& Ackoff ,1954); lexicographies Podinovsky (Podinovsky, 1972; Podinovsky, 2002; Podinovsky, 2003);

- Constructions of the generalised criterion - the generalised criterion Podinovsky (Podinovsky, Grumondz, Osipova, \& Alekseev, 1996; Podinovsky, 2007); max (min) convolutions (Germeer, 1971); multiplicate and polyadditive convolutions of Kini (Kenye \& Rifa, 1981); value functions, methods of "evasion" of Charnsa-Cooper (Charsnes \& Cooper, 1961); the normalized sedate metrics of Zeleny (Zeleny, 1973); transformation of frequencies of preferences of Thurstone (Thurstone, 1959); transformation of frequencies of reference to a class of Rosner (Rosner, 1956);

- Methods of "evasion”-Szidarovsky (Szidarovsky, 1978); estimations of affinity to a basic trajectory of Hwang and Lin (Hwang \& Lin, 1987); Aggregations and rangings of alternatives about multisign ideal situations (Petrovsky, 2009); 
- Methods of casual randomization (Nogin, 2002).

These methods do not always demand knowledge quantitative or range estimations, and do not approach to problems which even on pair comparison of estimations by criteria, as a rule, lead to their equality.

\section{The Condition of a Question on Definition of Importance of Criteria}

Now it is considered that weight of criteria - the most difficult place in a decision-making problem (DSS). Manipulating scales are possible to receive any rating which is only possible to wish. Earlier in the overwhelming majority of weight cases simply appointed, proceeding from intuitive representation of the person of the making decision (PMD) about comparative importance of criteria. Thereby, the rating turns out actually "appointed" (Gorsky, 2009). By this time, researches show that PMD or the expert is not capable to appoint directly to criteria correct numerical weight. Special selection of correct procedure of reception of scales is necessary. It is proved that the weight of criteria are not always necessary (Podinovsky, 2007; Borisov, Krumberg, \& Fedorov, 1990). In the majority of problems criterion X, there is enough type information that "it is more important than criterion Y". Further special procedures on the basis of individual rankings are necessary to construct the generalised. It can be made at different methods. It is considered the most correct method medians of Kemeni and Snell (Kemeny \& Snell, 1972) and Cook-Sejforda. For a median finding, first of all, it is necessary to set a way of definition of distance between rankings. After that, it is necessary to find such ranking the total distance from which before all set expert rankings would be the minimum distance. Required ranking also will be a median of Kemeni. It is very important that by doing so, you can get a consolidated view of experts, not discarding any opinions, because when you build a median, substantially you will takes into account all individual rankings. Lack of ways to determine weights of criteria is its laboriousness.

\section{To a Question on Convolution}

The incorrectness of operation of summation in additive convolution (1) is proved in the classical book of the American mathematicians of Kini and Rajfa (Kenye \& Rifa, 1981). It is proved that the similar formula is correct only when all criteria are in pairs and independent on preference.

\section{The Weighed Sum of Estimations}

The incorrectness of calculation of the weighed sum of estimations occurs, first of all, that attempts to receive from the expert the information in such form in which it cannot give it with sufficient reliability are frequent. It is authentically established that experts badly give estimations in a numerical kind. Much more reliably they work with ranks. And it is the most confident-in verbal estimations. Other error of linear convolution consists in application in this case conclude a postulate: "the low estimation by one criterion can be compensated an appreciation in another way”. The aspiration to average conducts to leveling of distinctions in individual judgments of experts, to smoothing and elimination of the extreme points of view in which rational grain can consist. However, this postulate is true for all models of a comparative estimation of "quality".

For this reason, except linear convolution, others are offered much. For example, multiplication, an additive difference of estimations (Petrovsky, 2009) and poly additive convolution in which the operator of summation, is replaced on the operator of product (Kenye \& Rifa, 1981). It is used in the models based on a postulate "the low estimation at least by one criterion, involves low value of function of utility". 


\section{Intermediate Conclusions and Statement of Problems}

From the approaches set forth above for little-changeable estimations by the best it is considered, when the weightiness of criterion is carried out by results of examination after reception of estimations from a commission of experts. First, this approach allows to define the factor of importance of each criterion more precisely. Now it is considered that the V-second importance of criterion is constant and does not depend on the expert, and also from a problem situation for which conditions the estimation is made.

In the given work, the method of a finding of distances from trajectories of alternatives by each criterion to the constructed ideal estimation is offered at group examination with definition of factors of importance of criteria by a method of a finding of a generality.

The algorithm of an offered method looks like:

- At a great number of indicators there are the primary factors replacing with self initial indicators;

- There are factors of regress for each factor and an indicator, on a generality;

- Each estimation of alternative corresponding to each indicator is multiplied by the factors of regress found in item 2. Thus, there are trajectories of each alternative taking into account a generality in the criteria put in initial estimations;

- On the constructed trajectories of alternatives of each criterion there is the greatest (or the least—depending on the problem decision on Max or Min) an estimation— “record";

- Under various metrics the matrix of distances of deviations of trajectories of alternatives from "an ideal" (record) trajectory is under construction;

- On size of distance for each alternative, the last are ranged and, thereby, the best is defined.

\section{Theoretical Data on Possibility of Allocation of a Generality}

Expert estimations always contain both objective and subjective components. The decision of a problem of a choice of the best alternative (object) generates a problem: how to reveal human factors and to reduce them to a minimum, and how to reveal objective, the general for all estimations to a component (generality).

Early studies in the field of generality allocation contain in work of Bates and Granger (Bates \& Granger, 1969) and then in work of Newhold and Granger (Newhold \& Granger, 1974). Authors recognize that even rejected, the weak importance of criteria of their estimation almost always contain some useful independent information which they can bring in the general estimation. Associations of independent evaluations of options are both types of information, both subjective and objective. With private estimations only one common requirement is that they must not contain bias.

Way of association of the private estimations, the put Bates and Granger and Newhold and Granger, consists in presenting the combined estimation in the form of the weighed sum of private estimations:

$$
\widehat{x}_{k}(t)=\sum_{i} k_{i} x_{i}(t)
$$

where

$x_{i(t)}-i$ : the private estimation of a variant received for a combination of conditions $t$;

$k_{i}$ : the weight given to $i$ th private estimation.

The sum of all scales is equal 1 , and weight is in an interval $[0,1]$. It is obvious that the basic problem which here arises-definition of scales $k_{i}$ as they will define quality of an incorporated estimation and a 
definitive estimation of variants.

There are some ways of definition of scales. Initial preconditions of such method consist in the following:

(1) it is supposed that efficiency of separate estimations does not change eventually (we will designate dispersions of errors for two estimations at any moment $t$ through $\sigma_{1}{ }^{2}$ and $\sigma_{2}{ }^{2}$ );

(2) it is supposed also that both estimations do not contain a regular error.

Then the incorporated estimation turns out in the form of a linear combination of two estimations, and the weight $k$ is set by the first of them, and the weight of the second is equal (1-k).

The dispersion of an error $\sigma_{0}^{2}$ is equal in an incorporated estimation

$$
\sigma_{0}^{2}=k^{2} \sigma_{1}^{2}+(1-k)^{2} \sigma_{2}^{2}+2 \rho k \sigma_{1}(1-k) \sigma_{2}
$$

where

$k$ : the weight expressed in percentage and set first estimation;

$p$ : correlation factor between errors in the first and second estimations.

As the private estimations received for several various situations, criteria, experts are presented by the limited samples received, statisticians are casual and have errors, the statistical importance, a corridor of errors on a certain significance value and so forth from here a natural question is to try to unite private estimations on the basis of statistical procedures. The application of the factorial analysis can be the realization of such approach to generality allocation. As has offered Ershov (Ershov, 1973), factors of the uniting equation here are on the basis of parameters of distribution of the multidimensional random variable representing set of deviations of private estimations from a generality.

The idea of application of the factorial analysis for the construction of the generalized estimation is based that the private estimations received for $n$th variant $x_{n}(n=1,2, \ldots, \mathrm{N})$, are external expression of some real-life, but directly immeasurable size (true). It is also accepted as the generalized estimation. Therefore, between private estimations strong correlation can take place.

It can be written down so:

$$
x_{i}=g_{i} f+e_{i}
$$

where

$x_{i}$ : private estimations;

$f$ : the generalized estimation causing a regular variation of private estimations and correlation communication between them;

$g_{i}$ : loading (weight) of the generalized estimation $f$ on a private estimation $x_{i}$;

$e_{i}$ : the rest (a characteristic indicator), defining that part of an estimation $x_{i}$ which change is caused by action of individual or subjective influences of experts, criteria, situations.

Expression (4) is a model of the factorial analysis with one general factor. Thus it is possible to express the general factor (the generalized estimation) through a linear combination of private estimations with scales $a_{i}$ :

$$
f=a_{1} x_{1}+a_{2} x_{2}+\ldots+a_{n} x_{n}
$$

Values of the generalized estimation can be found, using a regression method offered by Thomson (Thomson, 1960).

As measure of quality of an estimation of the factor $f$ by means of the equation (5), the factor of plural correlation $R^{2}$ can serve. It define from the formula 


$$
R^{2}=a_{1} g_{1}+a_{2} g_{2}+\ldots+a_{n} g_{n}
$$

Factors $a_{i}$ in the formula (5) are scales of importance of criteria in the generalised indicator $f$.

\section{Example of Practical Allocation of Factors of Importance of Criteria a Generality Finding, a Factorial Method, and Constructions of Distances from "Ideal” for Each Alternative}

Let's consider the following problem of a choice vender the software of appendices to Storehouses to the data of certain type (see Figure 1):

- In a problem, there are 5 alternatives (after reduction of set of alternatives, the removal which is not corresponding to demanded indicators);

- Number of experts equally 5;

- Number of criteria (indicators) equally 28;

- Calculations are conducted on 1st problem situation (this condition is not basic and it is accepted only for reduction of the size of a matrix of estimations);

- Estimations resulted in the form of conformity degree to the exposed requirements 5-greatest estimation, 1 -the least satisfaction;

- For an illustration in the initial data of an estimation of experts are resulted already coordinated.

Let's calculate factors of regress of importance of criteria on a generality.

As a result of calculation for 20 criteria which have been entered into set of Pareto, it has turned out 4 main components to explain $100 \%$ of dispersion (see Figure 2).

For allocation of a generality from private estimations and construction of trajectories of the alternatives, the received factors of regress on a generality are necessary for increasing by values of estimations of alternatives, and in normalized expression to increase on normalized variables (see Figure 2).

As in the initial data, the full satisfaction to requirements corresponds to the highest estimation 5 . We will find "a record" (ideal) trajectory (on Figure 2-the Maximum value of a generality). The matrix of trajectories of alternatives and a record trajectory (see Figure 2) represents the initial data for calculation of distances between them of various metrics.

As an example in Table 3, the matrix of distances calculated on Euclidean to the metrics is resulted. The best variant under this metrics is alternative VAR001, as having the best affinity to an ideal trajectory (a rank 1). In Table 1, the ranks of variants received on distances of other metrics are illustrated.

From Table 1, it follows that on nearness of trajectories of alternatives to an ideal trajectory, the best variant at all metrics is vender Arcplan, whose appendices to Warehouse of the data most full correspond to the exposed requirements. It is also possible to note high degree of a coordination of the received decisions at various metrics.

Comparisons of the received results with results of other known methods have shown full identity with a method of definition of importance of criteria through their entropy (Hwang \& Lin, 1987).

From Table 2, it is visible that identical results have given methods Hwang and Lin (TOPSIS), a generality with a distance of Euclidean, a generality with a square-law measure of Euclidean, and a generality with a measure of Minkovsky. Results of application of methods are: (1) a generality with a measure of Chebyshev; (2) SAW with additive convolution; (3) multiplicate convolution do not coincide with results of modified method TOPSIS and with calculation of factors of importance of criteria through entropy of estimations of variants. 


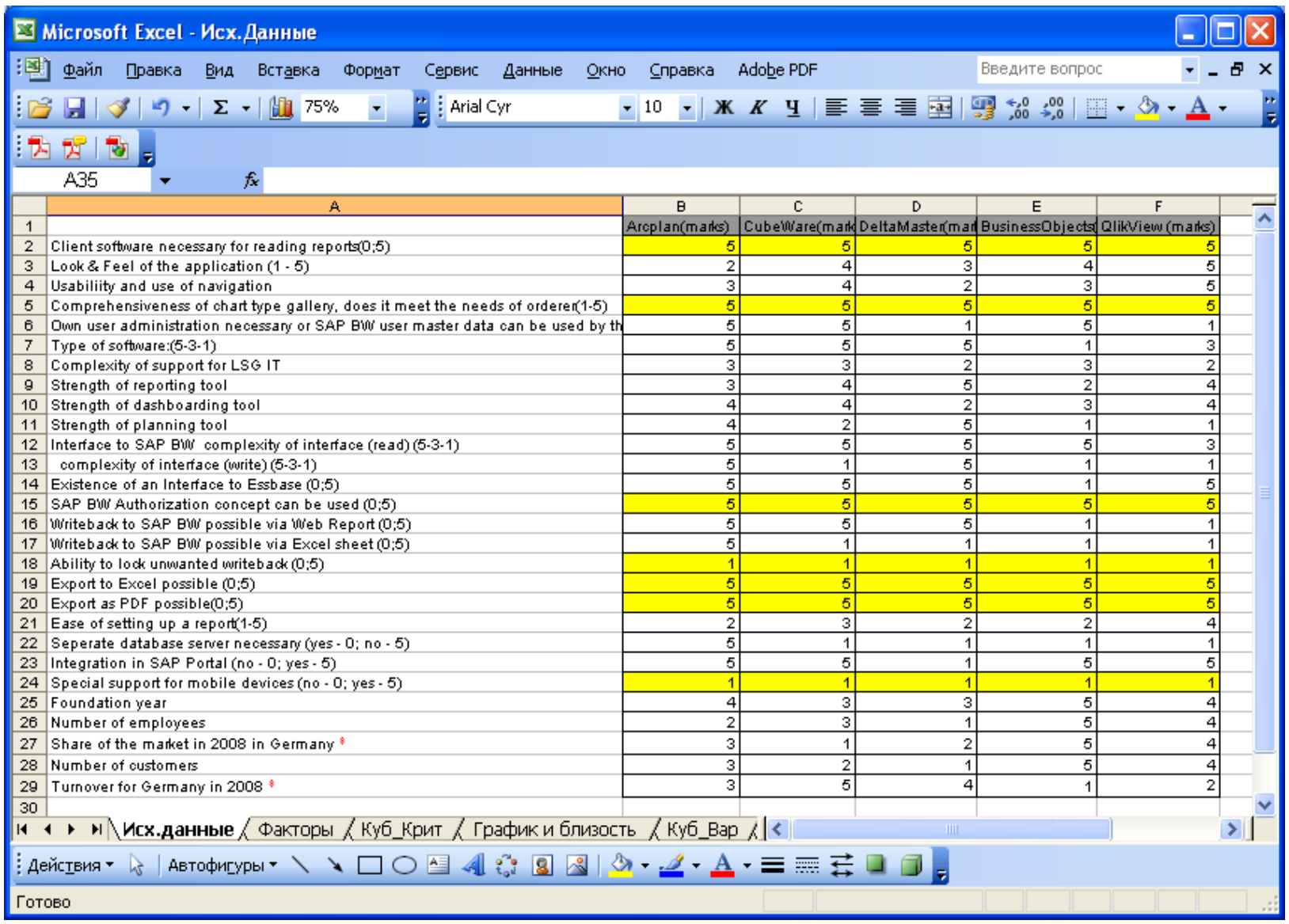

Figure 1. The initial data in the form of degree of conformity of indicators of alternatives to requirements.

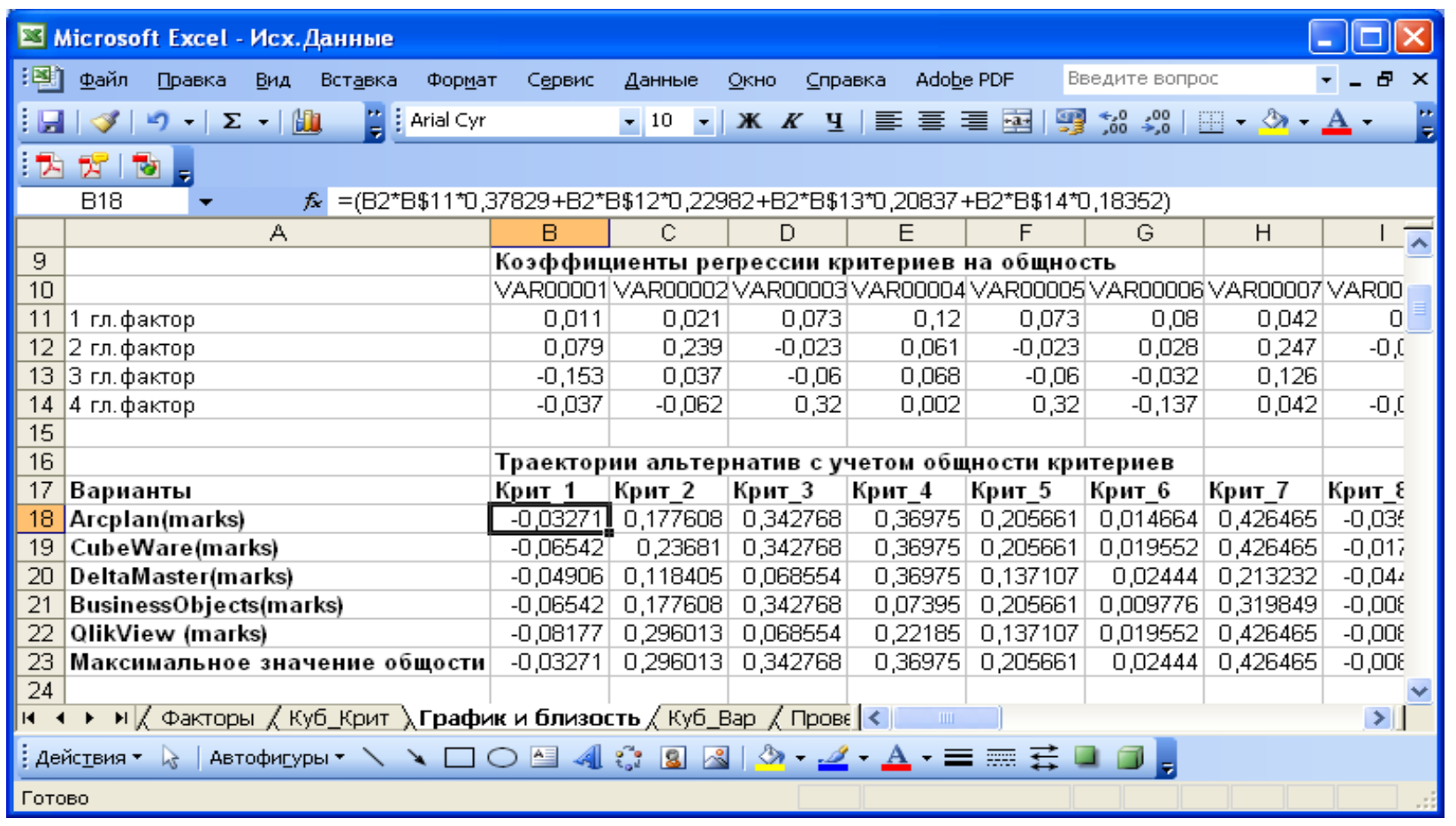

Figure 2. An example of calculation of trajectories of alternatives. 
Table 1

Rankings of Alternatives for Distances of Different Metrics

\begin{tabular}{llllll}
\hline Metrics of distances & Alternative_1 & Alternative_2 & Alternative_3 & Alternative_4 & Alternative_5 \\
\hline Euclidean to the metrics & 1 & 2 & 3 & 5 & 4 \\
A Square-law measure of Euclidean & 1 & 2 & 3 & 5 & 4 \\
A measure of Chebyshev & 1 & 2 & 5 & 3 & 4 \\
A measure of Minkovsky & 1 & 2 & 3 & 5 & 4 \\
\hline
\end{tabular}

Note. Source: Own calculation.

Table 2

Correlation Between Results of Application of Various Methods

\begin{tabular}{|c|c|c|c|c|c|c|c|}
\hline & & Weight & criteria for $g$ & & & & \\
\hline & $\begin{array}{l}\frac{n}{\omega} \\
\tilde{\sigma} \\
.\end{array}$ & 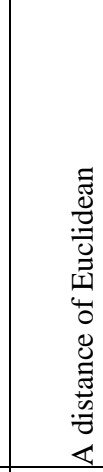 & 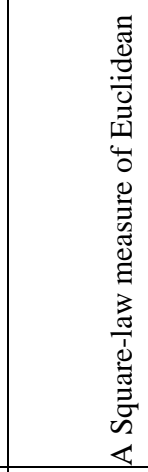 & 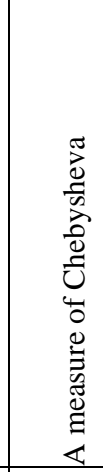 & 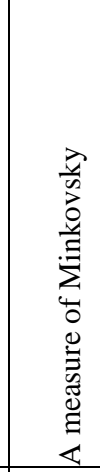 & 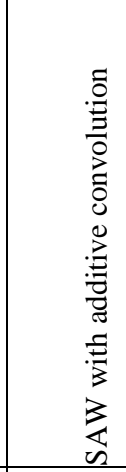 & 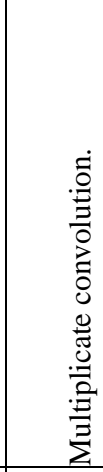 \\
\hline Topsis (Hwang and Lin) & 1 & & & & & & \\
\hline A distance of Euclidean & 1 & 1 & & & & & \\
\hline A Square-law measure of Euclidean & 1 & 1 & 1 & & & & \\
\hline A measure of Chebyshev & 0.6 & 0.6 & 0.6 & 1 & & & \\
\hline A measure of Minkovsky & 1 & 1 & 1 & 0.6 & 1 & & \\
\hline SAW with additive convolution & 0.6 & 0.9 & 0.9 & 0.5 & 0.9 & 1 & \\
\hline Multiplicate convolution & 0.5 & 0.9 & 0.9 & 0.7 & 0.9 & 0.8 & 1 \\
\hline
\end{tabular}

Note. Source: Own calculation.

Table 3

An example of Calculation of Distances on Euclidean to the Metrics

\begin{tabular}{lllllll}
\hline \multicolumn{7}{c}{ Euclidean Distance } \\
\hline
\end{tabular}

\section{The Conclusion}

The technique offered in article allows to search in private estimations of the alternatives corresponding to various criteria, problem situations and statements of group examination, factors of importance of criteria without iterations with the minimum expenditures of labor. The account received the importance of criteria in calculation of trajectories of alternatives leads to reception of affinity of alternatives to the ideal set constructed 
on "records". Calculation of a matrix of affinity under various metrics has shown a high coordination of results of ranging of alternatives under all metrics.

\section{References}

Anohin, A. M., Glotov, V. A., Pavelev, V. V., \& Cherkashin, A. M. (1997). Methods of determining importance coefficients of factors. Avtomatika i telemehanika, 8, 3-35 (Анохин, А. М., Глотов, В. А., Павельев, В. В., Черкашин, А. М. Методы определения коэффициентов важности критериев. Автоматика и телемеханика, 8, 3-35).

Bates, J. M., \& Granger, C. W. J. (1969). The Combination of Forecasts. Oper. Reser. Quart, 20 (4), 451-468.

Borisov, A. N., Krumberg, O. A., \& Fedorov, I. P. (1990). Decision-making on the base of fuzzy sets: Examples of using. Riga: Znaniye (Борисов, А. Н., Крумберг, О. А., Федоров, И. П. Принятие решения на основе нечетких моделей: примеры использования; Рига.: Знание).

Charchmen, C. W., \& Ackoff, R. (1954). An approximate Measure of Value. Operations Research, 2, 172-181.

Charsnes, A., \& Cooper, W. W. (1961). Management models and industrial applications of line programming. N.Y.: Wiley.

Ershov, E. B. (1973). About one method of combining particular forecasts. Statistical analysis of economic time series and forecasting: Statistical memoirs, XXII-XXIII. Moscow: Nauka (Ершов, Э. Б. Об одном методе объединения частных прогнозов. Статистический анализ экономических временных рядов и прогнозирование: Ученые записки по статистике. Т. XXII-XXIII. М.: Наука).

Germeer, J. В. (1971). Introduction to the operations research theory. Moscow: Nauka (Гермеер, Ю. Б. Введение в теорию исследования операций -М.: Наука)

Gmoshinsky, V. G., \& Flnorent, A. V. (1975). Theoretical basis of engineering forecasting. Moscow: Nauka (Гмошинский, В. Г., Флнорент, А. В. Теоретические основы инженерного прогнозирования М.: Наука).

Gorsky, П. (2009). Introduction to the discipline "Decision-making support” (Введение в дисциплину “Поддержка принятия решений”). Retrieved from http://www.pavel.gorskiy.ru

Hwang, Ch.-L., \& Lin M. -J. (1987). Group decision making under multiple criteria: Methods and applications. Berlin: Springer-Verlag.

Kemeny, D., \& Snell, D. (1972). Cybernetic modeling. Moscow: Sovetskoe radio (Кемени, Д., Снелл, Д. Кибернетическое моделирование. М.: Советское радио).

Kenye, R. L., \& Rifa, Н. (1981) Decision making for multicriteria of preference and substitution. Moscow: Radio i svyaz (Кини, Р. Л., Райфа, Х. Принятие решений при многих критериях предпочтения и замещения, -М.: Радио и связь).

Makarov, I. M. (Ed.) (1971). Selection of approach to networks building (Макаров, И. М. и др. Выбор принципа построения сетей.). AnT, 4, 25-31.

Newhold, P., \& Granger, C. W. J. (1974). Experience with forecasting univariate time series and combination of forecasts. J. of Royal Statistical Society, 137(2), 131-164.

Nogin, V. D. (2002). Decision-making in multicriteria environment. Quantitative approach. Moscow: Fizmatlit (Ногин, В. Д. Принятие решений в многокритериальной среде. Количественный подход. -М.: Физматлит).

Petrovsky, А. В. (2006). Multicriteria ranking by conflicting data. Iskustvenny intellekt, 2, 5 (Петровский, А. Б. Многокритериальное ранжирование объектов по противоречивым данным. Искусственный интеллект, 2, с.5).

Petrovsky, A. B. (2009). Decision making theory. Moscow: Akademiya (Теория принятия решений.-М.: Издательский дом «Академия»). И. М. Макаров (Еd.) (1971). Выбор принципа построения сетей. АнT, 4, 25-31.

Podinovsky, V. V. (1972). Lexicographic tasks of linear programming. Journal vychislitelnoy matematiki i matematicheskoy fiziki, 12(6), 568-571 (Подиновский, В. В. Лексикографические задачи линейного программирования. Журнал вычислительной математики и математической физики, 12(6), 568-571).

Podinovsky, V. V. (2002). The problem of estimation of importance factors as a symmetric-lexicographic problem of optimization. Avtomatika i telemehanika, 3, 150-162 (Подиновский, В. В. Задача оценивания коэффициентов важности как симметрически-лексикографическая задача оптимизации. Автоматика и телемеханика, 3, 150-162).

Podinovsky, V. V. (2003). The problem of estimation of importance factors as a symmetric-lexicographic problem of optimization. Automation and Remote Control, 64(3), 480-492.

Podinovsky, В. В. (2007). Introduction to the importance factors theory in multicriteria decision problem. Moscow: Fizmatlit (Подиновский, В. В. Введение в теорию важности критериев в многокритериальных задачах принятия решений. -М.: Физматлит). 
Podinovsky, V. V., Grumondz, V. T., Osipova, V. A., \& Alekseev, N. S. (1966). Methods of importance factors theory in dynamic design tasks. 1-st Moscow international conference on Operations Research, collected papers, 82-86. Moscow: CC RAS (Подиновский, В. В., Грумондз, В. Т., Осипова, В. А., Алексеев, Н. С. Методы теории важности критериев в задачах динамического проектирования. Сб.тр. 1-й Московской международной конференции по исследованию операций, 82-86. М.: ВЦ РАН).

Rosner, B. S. (1956). A new scaling technique for absolute judgment. Psychometrica, 21(4), 377-381.

Szidarovsky, R. I. (1978). Use of cooperative games in a multi-objective analysis of mining and environment. Proc. and International Conference, Madrid (pp. 11-15).

Thomson, G. H. (1960). The factorial analysis of human ability. London: London University Press.

Thurstone, L. L. (1959). The measurement of values. Chicago: University of Chicago Press.

Tintarev, Е. М., \& Trofimov, V. М. (1975). Approximation of importance coefficients by ranking functions (Тинтарев, Э. М., Трофимов, В. М. Аппроксимация коэффициентов важности функциями ранжирования). Ekonomika $i$ matematicheskiye metody, 11(7), 17-20.

Zeleny, M. (1973). Compromise programming in M.K. Starr and M. Zelleny, Columbia (p. 404). 